2. Васькова Ю.И. Методы стратегического анализа мясоперерабатывающих предприятий с учетом антикризисных элементов // Материалы науч.-практ. конф. / под ред. Е.Б. Дудниковой. - Саратов: ФГБОУ ВО Саратовский ГАУ, ООО «ЦеСАин», 2018. - С. 128-134.

3. Закшевская T.В. Стратегии антикризисного управления сельскохозяйственными предприятиями. Воронеж: ГНУ НИИЭОАПК ЦЧР России, ФГБОУ ВПО Воронежский ГАУ, 2013. - 203 с.

4. Котлер Ф., Келлер К.Л. Маркетинг. Менеджмент / пер. с англ.; под ред. Е. Масловой. - СПб.: Питер, 2014. - 800 c.

5. Мащенко B.Е. Системное корпоративное управление. - М.: Сирин, 2003. - 132 с.

6. Портер М., Самплер Дж., Прахалад С.К. Курс MBA по стратегическому менеджменту / пер. с англ. М.: Альпина Бизнес Букс, 2005. - 608 с.

7. Томпсон А.А., Стрикленд А.Дж. Стратегический менеджмент. Искусство разработки и реализации стратегии. - М., СПб., Киев: Вильямс, 2003. - 576 с.
8. Тренев Н.Н. Стратегическое управление: учеб. пособие для вузов. - М.: «Издательство ПРИОР», 2000. -288 c

Васькова Юлия Ивановна, соискатель кафедры «Менеджмент и внешнеэкономическая деятельность в АПК», Саратовский государственный аграрный университет имени Н.И. Вавилова. Россия.

Глебов Иван Петрович, $\partial-p$ экон. наук, проф. кафедры «Менеджмент и внешнеэкономическая деятельность в АПК», Саратовский государственный аграрный университет имени Н.И. Вавилова. Россия.

410012, г. Саратов, Театральная пл., 1.

Тел.: 89603551021; e-mail: rygyk@list.ru.

Ключевые слова: стратегическое управление; антикризисное управление; эталонные стратегии; классификация стратегий; управление мясоперерабатывающим предприятием.

\title{
SYSTEMATIZATION OF REFERENCE STRATEGIES IN THE ASPECT OF ANTI-CRISIS MANAGEMENT OF MEAT PROCESSING ENTERPRISES
}

Vas'kova Yulia Ivanovna, Competitor of the chair "Management and Foreign Economic Activity in Agriculture", Saratov State Agrarian University named after N.I. Vavilov. Russia.

Glebov Ivan Petrovich, Doctor of Economic Sciences, Professor of the chair "Management and Foreign Economic Activity in Agriculture", Saratov State Agrarian University named after N.I. Vavilov. Russia.
Keywords: strategic management; crisis management; reference strategies; classification of strategies; management of meat processing enterprise.

The article describes various approaches to the formation of enterprise management strategy, types of reference strategies of meat processing enterprise management in the anti-crisis aspect are systematized, the expediency of the choice of strategy depending on the situation is grounded.

\section{ОСОБЕННОСТИ СОВРЕМЕННОЙ КЛАССИФИКАЦИИ ПРОДОВОЛЬСТВИЯ И СЕЛЬХОЗСЫРЬЯ ПО МЕСТУ ПРОИСХОЖДЕНИЯ}

\author{
ВОРОТНИКОВ Игорь Леонидович, Саратовский государственный аграрный университет \\ имени Н.И. Вавилова
}

МУРАВЬЕВА Марина Владимировна, Саратовский государственный аграрный университет имени Н.И. Вавилова

ПЕТРОВ Константин Александрович, Саратовский государственный аграрный университет имени Н.И. Вавилова

Представлены особенности современной классификации продовольствия и сельхозсыръя по месту происхождения с учетом международной обстановки. Дается характеристика актуальных направлений классификации в связи с введенньми ограничениями на импорт отдельных видов продукиии в связи с реализацией санкционной политики государства. Предложены классификационные группировки продовольствия и сельхозсыръя по отдельным направлениям классификации. Рассматриваются проблемы по выявлению страны происхождения товара, особенности таможенного оформления продукции и сельхозсыръя.

Введение. Актуальность проблемы классификации продовольствия и сельхозсырья по месту происхождения обострилась в связи с введением санкций против нашей страны и контрсанкций, в которых указаны страны, имеющие ограничения на поставки продовольствия [3, 4].

Проблема классификации стран изучалась экономистами с различных позиций: уровня благосо- стояния населения, объемов ВВП, внешнего долга, продовольственной обеспеченности, территориальной структуры хозяйства и других показателей. Наибольшую популярность получила классификация стран по уровню экономического развития на развитие и развивающиеся, принятая $\mathrm{OOH}$, а также классификация Всемирного Банка. Классификацией стран по различным показателям занимались такие 
известные ученые, как Б.М. Болотин, В.Л. Шейнис (типологическая классификация развивающихся стран и территорий), А.С. Фетисов, В.С. Тикунов (оценочно-типологический подход), Я.Г. Машбиц (тенденции индустриализации), В.В. Вольский (типология стран) и др. [6]. Тем не менее, с точки зрения продовольственной безопасности наиболее важной характеристикой является обеспеченность продовольствием в расчете на душу населения [1]. В современных условиях необходимо также выделение стран санкционного списка или стран, в отношении которых заключены двухсторонние договора о торговле продовольствием и сельхозсырьем.

Методика исследований. Методологию исследования составили системный анализ, теория прогнозирования, организации и динамического равновесия. При подготовке статьи были использованы общенаучные методы познания: логический, исторический, монографический, анализа и синтеза, сравнений, научной абстракции, а также методы экономического анализа: сравнения, группировки, графический, ряды динамики, а также другие экономико-математические и статистические методы исследования. Информационной базой исследования являются труды отечественных и зарубежных ученых-экономистов, статистические справочники Федеральной службы государственной статистики Российской Федерации, Федеральной таможенной службы Российской Федерации, нормативно-правовые документы, официальные материалы Министерства сельского хозяйства России, аналитические обзоры, а также разработки авторов по изучаемой проблематике.

Результаты исследований. В вопросе контроля страны происхождения товара таможенные органы руководствуются действующими нормативными документами, например, Таможенным кодексом Евразийского экономического союза [5]. В данном случае необходимо различать фактическую страну происхождения товара и факт подтверждения указанной страны происхождения, чем пользуются многие товаропроизводителя, чтобы в определенной степени обойти санкции.

Следует отметить, что в качестве страны происхождения может приниматься группа стран, Таможенный союз, регион или часть страны, что усложняет процедуру идентификации страны происхождения товара. По общему правилу документами, подтверждающими страну происхождения товаров, служат декларации происхождения товара и сертификат его происхождения.

Важной особенностью при идентификации страны происхождения продовольственных товаров является степень его переработки. Например, если в производстве товаров участвуют две и более страны, то страной происхождения считается та, в которой были произведены последние операции по переработке или изготовлению товаров, отвечающих условиям достаточной переработки.
При изучении вопросов классификации стран в первую очередь необходимо обратить внимание на действующую классификацию Всемирного Банка. Очевидно, что для целей идентификации продовольствия и сельхозсырья такая классификация не подходит (табл. 1).

Таблица 1

\section{Классификация стран по месту происхождения} Всемирного Банка

\begin{tabular}{|c|l|c|}
\hline $\begin{array}{c}\text { Группа } \\
\text { стран }\end{array}$ & \multicolumn{1}{|c|}{ Наименование } & $\begin{array}{c}\text { Количество } \\
\text { стран в группе }\end{array}$ \\
\hline 1 & Восточная Азия и Океания & 38 \\
\hline 2 & Европа и Центральная Азия & 58 \\
\hline 3 & Латинская Америка и Карибские острова & 42 \\
\hline 4 & Средне-восточная и Северная Африка & 21 \\
\hline 5 & Северная Америка & 3 \\
\hline 6 & Южная Азия & 8 \\
\hline 7 & Африка к югу от Сахары & 48 \\
\hline
\end{tabular}

В целях реализации стратегии импортозамещения и формирования эффективной государственной политики импортозамещения необходимо обосновать классификацию продовольствия и сельхозсырья по месту происхождения исходя из современных макроэкономических факторов.

География импорта продовольственных товаров в Российскую Федерацию достаточно разнообразна. Можно выделить страны Дальнего зарубежья, наибольшую долю в данной группе составляют страны EC (23,4 \% в 2017 г.), а также государства - участники СНГ (19,1 \% в 2017 г.) (табл. 2). При анализе структуры импорта необходимо руководствоваться товарной номенклатурой внешнеэкономической деятельности - это классификатор товаров, используемый при проведении таможенных операций декларантами и таможенными инспекторами. Ставки импортной и экспортной пошлины зависят от того, к какому коду данной номенклатуры относится товар. Сегодня актуальность приобретает также проблема ограничения импорта продовольствия и сельхозсырья из различных стран - ранее ограничения действовали по принципу выделения вида товара (например, при выявлении содержания в нем опасных для здоровья веществ). В настоящее время ограничению подвергаются отдельные товары из определенных стран, что приводит к необходимости классификации не только вида продовольствия и сельхозсырья, но и места его происхождения.

Классификационные группировки стран происхождения продовольствия и сельхозсырья могут быть различны, но для решения задач импортозамещения целесообразно применять представленные на рис. 1.

В современных условиях в первую очередь формируются группы стран, поставляющие продовольствие и сельхозсырье на территорию Российской Федерации исходя из норм Таможенного регулирования, в том числе ограничений - санкционный список, повышенные таможенные ставки и другие, а также преференции - страны Тамо- 
Таблица 2

География импорта продовольственных товаров в Российскую Федерацию [2]

\begin{tabular}{|c|c|c|c|c|c|c|}
\hline \multirow[b]{2}{*}{ Показатель } & \multicolumn{2}{|c|}{2015 г. } & \multicolumn{2}{|c|}{2016 г. } & \multicolumn{2}{|c|}{2017 г. } \\
\hline & 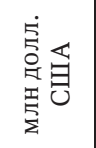 & $\begin{array}{l}\overrightarrow{0} \\
0 \\
0 \\
\vdots \\
\vdots \\
0 \\
0 \\
\infty\end{array}$ & 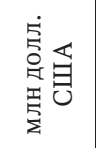 & $\begin{array}{l}\vec{D} \\
0 \\
0 \\
\vdots \\
\vdots \\
0 \\
0 \\
\infty\end{array}$ & 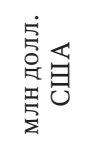 & $\begin{array}{l}\overrightarrow{2} \\
0 \\
\vdots \\
\vdots \\
\vdots \\
0 \\
\infty \\
\infty\end{array}$ \\
\hline $\begin{array}{l}\text { Продовольственные } \\
\text { товары и сельскохозяй- } \\
\text { ственное сырье } \\
\text { (кроме текстильного) } \\
\text { для их производства - } \\
\text { всего }\end{array}$ & 26457 & 100 & 24902 & 100 & 28819 & 100 \\
\hline $\begin{array}{l}\text { В том числе: } \\
\text { страны Дальнего } \\
\text { зарубежья }\end{array}$ & 22175 & 83,8 & 20407 & 81,9 & 23318 & 80,9 \\
\hline Страны EC & 5684 & 21,5 & 5632 & 22,6 & 6735 & 23,4 \\
\hline Аргентина & 742 & 2,8 & 616 & 2,5 & 579 & 2 \\
\hline Бразилия & 2554 & 9,7 & 2189 & 8,8 & 2477 & 8,6 \\
\hline Египет & 361 & 1,4 & 288 & 1,2 & 403 & 1,4 \\
\hline Израиль & 307 & 1,2 & 268 & 1,1 & 297 & 1 \\
\hline Иран & 204 & 0,8 & 233 & 0,9 & 273 & 0,9 \\
\hline Исландия & 95,5 & 0,4 & 7,2 & 0 & 7,3 & 0 \\
\hline Китай & 1541 & 5,8 & 1621 & 6,5 & 1769 & 6,1 \\
\hline Марокко & 343 & 1,3 & 402 & 1,6 & 388 & 1,3 \\
\hline Пакистан & 131 & 0,5 & 105 & 0,4 & 66,6 & 0,2 \\
\hline Парагвай & 857 & 3,2 & 697 & 2,8 & 625 & 2,2 \\
\hline Сербия & 311 & 1,2 & 343 & 1,4 & 404 & 1,4 \\
\hline Турция & 1380 & 5,2 & 625 & 2,5 & 1057 & 3,7 \\
\hline $\begin{array}{l}\text { Фарерские острова } \\
\text { (Дания) }\end{array}$ & 277 & 1 & 280 & 1,1 & 370 & 1,3 \\
\hline Чили & 634 & 2,4 & 546 & 2,2 & 633 & 2,2 \\
\hline Эквадор & 1145 & 4,3 & 1211 & 4,9 & 1299 & 4,5 \\
\hline ЮАР & 239 & 0,9 & 200 & 0,8 & 263 & 0,9 \\
\hline $\begin{array}{l}\text { Государства - } \\
\text { участники СНГ }\end{array}$ & 4282 & 16,2 & 4496 & 18,1 & 5500 & 19,1 \\
\hline Азербайджан & 270 & 1 & 324 & 1,3 & 449 & 1,6 \\
\hline Беларусь & 3148 & 11,9 & 3236 & 13 & 3892 & 13,5 \\
\hline Украина & 336 & 1,3 & 134 & 0,5 & 168 & 0,6 \\
\hline
\end{tabular}

женного Союза, страны, с которыми заключены двухсторонние договоры и др.

На основе классификации продовольствия и сельхозсырья по месту происхождения и группировке ТН ВЭД Таможенные органы принимают решение о порядке ввоза товаров на территорию Российской Федерации (рис. 2).

Заключение. Классификация продовольствия и сельхозсырья по месту происхождения приобретает особую актуальность в современных условиях. Определение страны происхождения играет важную роль в случаях:

предоставления тарифных преференций для продовольствия и сельхозсырья, происходящих из определенных стран и территорий;

регулирования количественного ввоза продовольствия и сельхозсырья из данной страны или территории (установлением квот или иных ограничений);

принятия мер по защите окружающей среды, здоровья населения, защиты прав российских потребителей, общественного порядка, государственной безопасности и других жизненно важных интересов страны;

Классификация продовольствия и сельхозсырья по месту происхождения
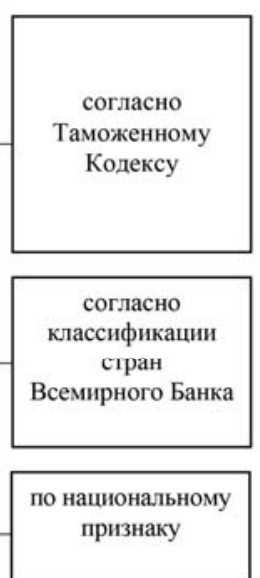
по санкционному
списку

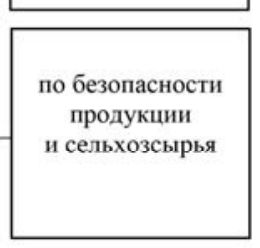
\begin{tabular}{|c|}
\hline по объему \\
международного \\
товарооборота \\
\hline
\end{tabular}

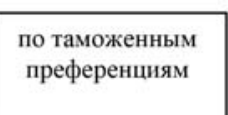
по субъективным
критериям

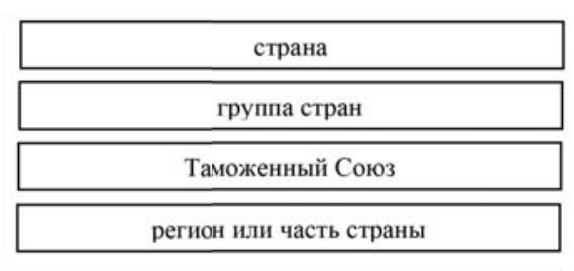

по терригориальному признаку
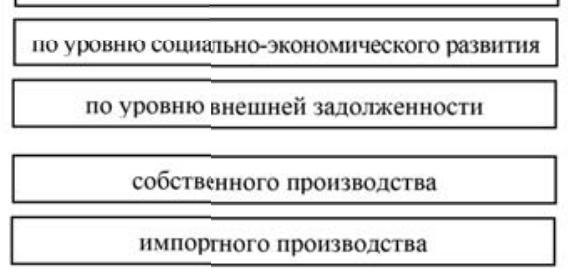

страны, входящие в санкционный список

страны, не входящие в санкционный список

страны первой группы (применяют определенные виды пестицидов, ядохимикатов, средств защиты растений, разрешено ГМО и др.)

страны второй группы (не применяют потенциально опасные агротехнологии)
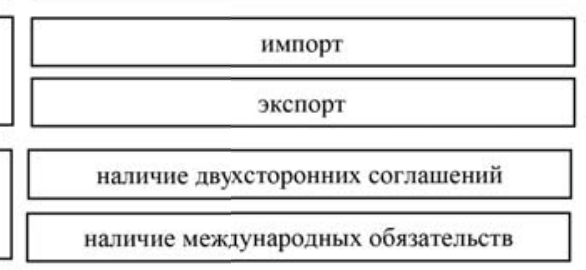

\begin{tabular}{|c|}
\hline международный имидж страны \\
\hline политические и социальные факторы \\
\hline
\end{tabular}

\section{Рис. 1. Критерии классификации продовольствия} и сельхозсырья по месту происхождения

признания продовольствия и сельхозсырья, происходящих с территории особых экономических зон РФ, а также стран - участниц Таможенного Союза, в том числе России, для применения механизмов, предусмотренных для этих зон и стран;

идентификации продовольствия и сельхозсырья, произведенной в странах санкционного списка для применения ограничительных мер.

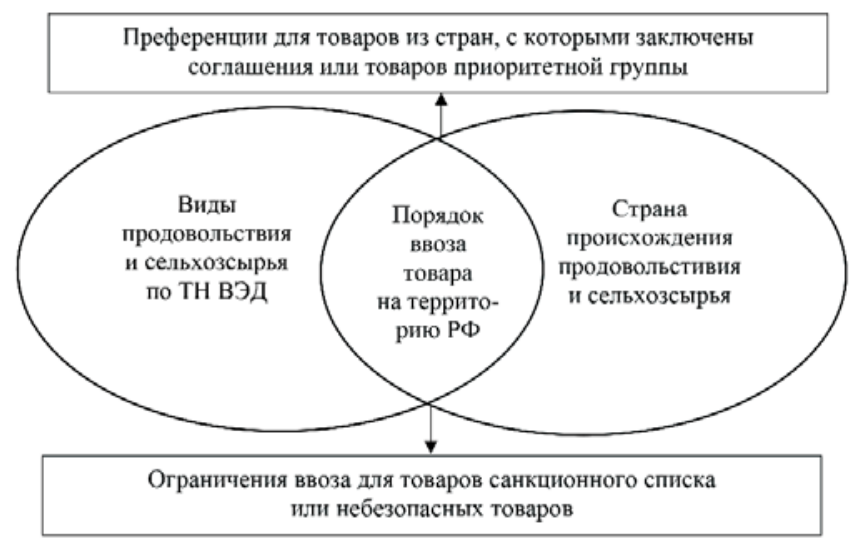

Рис. 2. Порядок ввоза продовольствия и сельхозсыръя на территорию Российской Федерации 


\section{СПИСОК ЛИТЕРАТУРЫ}

1. Воротников И.Л., Петров К.А. Проблемы развития российского сельского хозяйства в условиях интеграции в мировую агропродовольственную систему // Вестник Саратовского госагроуниверситета им. Н.И. Вавилова. - 2012. - № 1. - С. 71-73.

2. Официальный сайт Федеральной Таможенной службы. - Режим службы доступа: customs.staging. sitesoft.ru.

3. Суханова И.Ф., Лявина М.Ю. Методологические подходы к исследованию категории импортозамещения // Аграрный научный журнал. -2017. -№ 6. C. 94-96.

4. Суханова И.Ф., Лявина М.Ю. Экономические санкции: содержание, цели, мотивы, эффективность // Аграрный научный журнал. - 2018. - № 4. - С. 88-93.

5. Таможенный кодекс Евразийского экономического союза (Договор о Таможенном кодексе Евразийского экономического союза от 11 апреля 2017 года). Режим доступа: http://tktsrf.ru/.
6. Шишкин А.Ф., Шишкина Н.В.. Экономическая теория: учебник для вузов. - Т. 2. - М.: «Гуманитарный издательский центр Владос», 2017. - 1020 с.

Воротников Игорь Леонидович, д- $р$ экон. наук, проф., зав. кафедрой «Организащия производства и управление бизнесом в АПК», Саратовский государственный аграрный университет имени Н.И. Вавилова. Россия.

Муравьева Марина Владимировна, канд. экон. наук, доцент кафедры «Экономика АПК», Саратовский государственный аграрный университет имени Н.И. Вавилова. Россия.

Петров Константин Александрович, канд. экон. наук, доцент кафедры «Организация производства и управление бизнесом в АПК», Саратовский государственный аграрный университет имени Н.И. Вавилова. Россия.

410012, г. Саратов, Театральная пл., 1.

Тел.: (8452) 26-27-83.

Ключевые слова: классификация стран; продовольствие; сельскохозяйственное сырье; внешняя политика; страны; международная торговля.

\section{Статья выполнена при финансовой поддержке гранта РФФИ № 18-010-00607-а}

\section{FEATURES OF THE MODERN CLASSIFICATION OF FOOD AND AGRICULTURAL RAW MATERIALS ACCORDING TO THE PLACE OF ORIGIN}

Vorotnikov Igor Leonidovich, Doctor of Economic Sciences, Associate Professor of the chair "Organization of Production and Business Management in AIC”, Saratov State Agrarian University named after N.I. Vavilov. Russia.

Muravyeva Marina Vladimirovna, Candidate of Economic Sciences, Associate Professor of the chair "Economics of AIC", Saratov State Agrarian University named after N.I. Vavilov. Russia.

Petrov Konstantin Aleksandrovich, Candidate of Economic Sciences, Associate Professor of the chair "Organization of Production and Business Management in AIC", Saratov State Agrarian University named after N.I. Vavilov. Russia.
Keywords: country classification; food; agricultural raw materials; foreign policy; countries; international trade.

The features of the modern classification of food and agricultural raw materials according to the place of origin, taking into account the international situation are presented. Current directions of classification in connection with the introduced restrictions on the import of certain types of products in connection with the implementation of the sanction policy of the state are characterized. Classification groups of foodstuffs and agricultural raw materials in separate areas of classification are proposed. The problems of identifying the country of goods origin, features of customs clearance of products and agricultural raw materials are considered. 